\title{
Clinicopatbological Conference
}

\section{A Case of Chronic Lymphocytic Leukaemia}

\author{
PRESENTED AT THE ROYAL POSTGRADUATE MEDICAL SCHOOL
}

\section{Clinical History}

Dr. D. A. G. Galton (1): The patient (Case No. 293108; P.M. No. 12858), a development engineer of 58 working full time, attended Hammersmith Hospital on 22 July 1964. He had complained of increasing lassitude for about a year and of sweating attacks more recently. One month before a chest $x$-ray had been reported as normal, but a blood count showed a haemoglobin of $13.2 \mathrm{~g} . / 100 \mathrm{ml}$., and a leucocyte count of 44,100 /cu.mm., of which 41,000 were lymphocytes and 3,100 neutrophils. He had had his tonsils removed at the age of 9 years, but had been otherwise healthy apart from an attack of jaundice at the age of 20 while in the Lebanon.

He was in good general condition. There were discrete enlarged, non-tender, mobile lymph nodes up to $2 \mathrm{~cm}$. in diameter in both sides of the neck, axillae, and groins. The firm spleen was felt $7 \mathrm{~cm}$. below the costal margin, and the liver edge was palpable.

The haemoglobin was $14.8 \mathrm{~g} . / 100 \mathrm{ml}$; the packed cell volume $41.5 \%$; the mean corpuscular haemoglobin concentration $35.5 \%$; the platelets $115,000 /$ cu.mm.; and the leucocytes $43,000 /$ cu.mm., of which 40,400 were well-differentiated small lymphocytes, including many smudge cells. The direct antiglobulin reaction was negative. A bone-marrow aspiration yielded cellular fragments. There was heavy infiltration with well-differentiated small lymphocytes; $10 \%$ of the cells were residual haemopoietic cells, erythropoiesis was normoblastic, and megakaryocytes were present. The total serum protein concentration was $6.4 \mathrm{~g} . / 100 \mathrm{ml}$., with $4.6 \mathrm{~g}$. of albumin and $1.8 \mathrm{~g}$. of globulin. The serum uric acid concentration was $6.5 \mathrm{mg}$. $/ 100 \mathrm{ml}$. The chest $x$-ray was normal.

A diagnosis of chronic lymphocytic leukaemia was made, and he was observed without treatment for two months.

\section{Treatment and Progress}

On 17 September 1964 the symptoms and signs were unchanged, but the leucocyte count had risen to $115,000 /$ cu.mm. The haemoglobin was $14.0 \mathrm{~g} . / 100 \mathrm{ml}$. and the platelet count $190,000 /$ cu.mm. Chlorambucil at a daily dose of $10 \mathrm{mg}$. was administered for 28 days. After an initial increase the lymph nodes and spleen decreased in size during the next 2 months. The patient complained of pain in the throat and of difficulty in speaking. Hypertrophic lymphoid tissue was visible at the base of the tongue, and an $x$-ray confirmed the presence of irregular swelling there, while there was narrowing of the posterior nasopharyngeal space. The symptoms subsided without treatment. In March 1965 he complained of nasal obstruction. The left maxillary antrum was found to be infected, and mucopus was washed out.

On 22 April 1965 the lymph-node enlargement had recurred, and the tip of the spleen was again $7 \mathrm{~cm}$. below the costal margin. The liver edge was $10 \mathrm{~cm}$. below the costal margin.
The leucocyte count had risen to 53,000/cu.mm. (31,000 lymphocytes) from 12,000/cu.mm. (10,000 lymphocytes) on 10 October 1964, and the haemoglobin had fallen from 13.8 g. $/ 100 \mathrm{ml}$. to $13 \mathrm{~g} . / 100 \mathrm{ml}$. The platelet count was $180,000 /$ cu.mm. Chlorambucil therapy was started at a daily dose of $2 \mathrm{mg}$., increasing to $5 \mathrm{mg}$. on 10 June. By 19 August the lymph nodes had decreased only slightly in size, the spleen tip was $4 \mathrm{~cm}$. below the costal margin, and the liver $9 \mathrm{~cm}$. The haemoglobin was $13.5 \mathrm{~g} . / 100 \mathrm{ml}$., the platelet count $130,000 /$ cu.mm., and the leucocyte count $8,000 /$ cu.mm. (neutrophils 2,600, lymphocytes 4,200). Chlorambucil, $5 \mathrm{mg}$. on alternate days, was continued until 20 April 1967.

During these 2 years he remained well, apart from a mild attack of left mid-dorsal herpes zoster in March 1966, and continued at work. The physical signs were essentially unchanged; the haemoglobin concentration varied between 12.5 and $14.8 \mathrm{~g} . / 100 \mathrm{ml}$., the platelet counts between 100,000 and $180,000 /$ cu.mm., the neutrophil counts between 2,000 and $3,000 /$ cu.mm., and the lymphocyte counts between 4,000 and 7,000/cu.mm.

In April 1967 he developed a persistent left-sided purulent and occasionally bloodstained discharge from the nose and a dry cough. A chest $x$-ray showed enlargement of the paratracheal and bronchopulmonary lymph nodes. The left maxillary antrum was punctured and mucopus washed out. $\mathrm{He}$ complained of increasing lassitude, evening fever up to $102^{\circ} \mathrm{F}$. $\left(38.9^{\circ}\right.$ C.) and loss of $7 \mathrm{lb} .(3.3 \mathrm{~kg}$.) in weight. On 26 May 1967 the haemoglobin was $10 \mathrm{~g} . / 100 \mathrm{ml}$., the platelet count $85,000 /$ cu.mm., and the leucocyte count $8,000 /$ cu.mm, of which 470 were neutrophils. The direct antiglobulin reaction was negative, the serum folate $6 \mathrm{ng} . / \mathrm{ml}$, and the serum $B_{12}$ $390 \mathrm{pg} . / \mathrm{ml}$. The appearance of a bone-marrow aspirate was similar to that of the previous sample, but there was mild megaloblastic change. He was transfused with the red cells packed from 4 pints $(2.251$.) of blood.

He returned to work, but was readmitted on 20 June 1967 with severe diarrhoea (up to 20 bowel actions per day) and fever. He was dehydrated, but the physical signs were otherwise unchanged. Sigmoidoscopy to $19 \mathrm{~cm}$. showed a reddened mucosa with punctate haemorrhages.

\section{Further Investigations}

The haemoglobin was $11.4 \mathrm{~g} . / 100 \mathrm{ml}$, the platelet count $40,000 /$ cu.mm., and the leucocyte count $3,700 /$ cu.mm. (lymphocytes 3,200 , neutrophils 200 ). The serum protein was $5 \cdot 4$ g. $/ 100 \mathrm{ml}$., with $3.2 \mathrm{~g}$. of albumin, $2.2 \mathrm{~g}$. of globulin; IgG $350 \mathrm{mg}$. $/ 100 \mathrm{ml}$., IgA $120 \mathrm{mg}$., IgM $42 \mathrm{mg}$. 2 s.D. lower lognormal limits IgG 510, IgA 125, IgM 47). By December 1967 IgM had become undetectable and IgA had fallen to $55 \mathrm{mg}$. No pathogens were isolated from cultures of the blood, urine, or stool, or from throat swabs. A barium meal examination with follow-through and a bariúm enema showed no abnormality. A 
biopsy specimen from the rectal mucosa showed focal collections of lymphocytes invading the muscularis mucosae. The patient was treated with intravenous fluids and empirically with antibiotics. After hydration the haemoglobin was $8.3 \mathrm{~g} . / 100 \mathrm{ml}$. The symptoms abated and he was discharged.

Prednisone therapy at a daily dose of $40 \mathrm{mg}$. was started on 12 July 1967 . He became rapidly stronger, gained weight, and the size of the lymph nodes and spleen diminished. On 3 July the haemoglobin was $11.5 \mathrm{~g} . / 100 \mathrm{ml}$., the platelet count $180,000 /$ cu.mm., and the leucocyte count 32,000/cu.mm. (neutrophils 3,800). From 25 August to 5 September 1967 cyclophosphamide was administered at a daily dose of $100 \mathrm{mg}$. and the prednisone dosage was tailed off. The cyclophosphamide was discontinued because the neutrophil count had fallen to $450 /$ cu.mm.

On 26 September 1967 he was readmitted complaining of fever, persistent dry cough, and left-sided chest pain. He was febrile, with a temperature of $102^{\circ} \mathrm{F}$. $\left(38.9^{\circ} \mathrm{C}\right.$.), and had a blotchy, widespread erythematous rash on the face, limbs, and trunk. Blood cultures on three occasions yielded a growth of Staphylococcus albus. He was treated with trimethoprim and a long-acting sulphonamide (Gantanol) and the fever settled. From 30 September 1967 to the end of May 1968 he was treated with weekly injections of human gammaglobulin intramuscularly.

In mid-December 1967 he was well and working, and developed a paronychia on the left thumb for which he received tetracycline. On 23 December 1967 he was admitted with a fever of $103^{\circ} \mathrm{F}$. $\left(39 \cdot 4^{\circ} \mathrm{C}\right.$.). Three blood cultures remained sterile, but he responded to antibiotics administered empirically. From this time the dose of gammaglobulin was increased. He returned to work, but became partially deaf. The lymph nodes and the lymphoid tissue at the base of the tongue increased in size. $X$-ray therapy was administered to both sides of the face from 5 to 29 March 1968, and his hearing returned. He continued at work, but was readmitted on 23 May 1968 after a four-day attack of lethargy, fever to $100^{\circ} \mathrm{F} .\left(37 \cdot 8^{\circ} \mathrm{C}\right.$.), copious vomiting, and rapid weight loss.

On admission he was very ill, dehydrated, febrile, and cachectic. The lymph nodes had again enlarged, and the lower pole of the spleen was $12 \mathrm{~cm}$. below the costal margin.

The haemoglobin was $8.5 \mathrm{~g} . / 100 \mathrm{ml}$., the platelet count 75,000 /cu.mm., the leucocyte count $150,000 /$ cu.mm., of which 2,200 were neutrophils. The blood urea was $143 \mathrm{mg} . / 100 \mathrm{ml}$., serum calcium $6.5 \mathrm{mN}$, inorganic phosphate $3.5 \mathrm{mN}, \mathrm{Na} 138$ $\mathrm{mN}, \mathrm{K} 3.5 \mathrm{mN}$, uric acid $13.3 \mathrm{mg} . / 100 \mathrm{ml}$. An intravenous pyelogram showed no abnormality other than slow excretion. $\mathrm{He}$ was treated with intravenous fluids, blood transfusion, allopurinol, and antibiotics. On 10 June 1968 the blood urea was still $82 \mathrm{mg} . / 100 \mathrm{ml}$. He was sent home improved but very weak and not fit to work. He was readmitted on 13 July in a cachectic condition, severely dehydrated.

The haemoglobin was $7.6 \mathrm{~g} . / 100 \mathrm{ml}$., the platelet count 30,000 /cu.mm., the leucocyte count $330,000 /$ cu.mm., of which 6,600 were neutrophils. The blood urea was $249 \mathrm{mg} . / 100 \mathrm{ml}$., $\mathrm{Na}+135 \mathrm{mN}, \mathrm{K}+3.7 \mathrm{mN}, \mathrm{Cl}^{-} 96 \mathrm{mN}$, uric acid $8.5 \mathrm{mg} . /$ $100 \mathrm{ml}$., calcium $6.3 \mathrm{mN}$, alkaline phosphatase $24 \mathrm{~K} . A$. units. The creatinine clearance was $13 \mathrm{ml} . / \mathrm{min}$., the urinary $\mathrm{Na}^{+}$ excretion varied from 175 to $410 \mathrm{mEq} / 24 \mathrm{hr}$., and the urea excretion from 11 to $30 \mathrm{~g}$. $/ 24 \mathrm{hr}$. During admission he complained of back pain, and $x$-rays showed collapse of several vertebral bodies with generalized demineralization.

\section{Further Progress}

A salt-losing state was diagnosed and was treated with intravenous saline and subsequently with salt tablets, 8 to $9 \mathrm{~g}$. daily, the lower dose being given when ankle oedema appeared. His condition improved. He was transfused, and gammaglobulin injections were resumed. He was started again on prednisone 20 to $40 \mathrm{mg}$. and cyclophosphamide $100 \mathrm{mg}$. daily; the former was administered for 5 weeks, the latter until 2 January 1969. The leucocyte count fell to $4,000 /$ cu.mm., of which 200 were neutrophils, on 10 October 1968. $X$-rays showed thinning of the lumbar spine, gross collapse of the body of the 8th thoracic and of the 2nd lumbar vertebra, and partial collapse of the bodies of the 1st and 4th. There were multiple small lytic lesions in the pelvis and in the femoral heads, irregularity of the bone structure of the pubic rami having been noted in films taken on 28 May 1968. A spinal support was fitted and he was able to walk. He returned home on 13 August 1968. On 26 September he developed sudden severe pain in the back and in the left hip and was readmitted. He was emaciated, and had marked corneal calcification.

$X$-rays on 1 October 1968 showed collapse of several lower thoracic vertebral bodies. The serum calcium concentration was $6.3 \mathrm{mN}$, inorganic phosphate $2.3 \mathrm{mN}$, alkaline phosphatase 11 K.A. units.

He was treated with Sandoz phosphate tablets $4 \mathrm{~g}$. daily, instructed to drink 31 . of water daily, and he returned home. The pain improved, but he was able to walk only with some difficulty because of weakness of the legs, and he returned to work. He lost more weight and developed a gibbus at the level of the 12th thoracic vertebra. He remained fairly well until 25 December 1968, when severe back pain recurred and he developed diarrhoea. On 27 December he discontinued the phosphate tablets and the diarrhoea stopped. The pain was partially controlled with analgesics. On 2 January 1969 the axillary lymph nodes and the spleen were larger and the leucocyte count had increased to $50,000 /$ cu.mm. Cyclophosphamide was discontinued. The pain increased and he was admitted for palliative radiotherapy. From 14 January to 7 February 1969 he received 1,900 rads to the lumbar spine without relief of pain. He became weaker, febrile, began to bleed from the gums, and was readmitted on 14 February 1969.

$X$-rays showed widespread lytic deposits in the ribs and shoulder girdles. The haemoglobin was $6.9 \mathrm{~g} . / 100 \mathrm{ml}$, the platelet count was $4,000 /$ cu.mm., and the leucocyte count 1,400 /cu.mm., of which 14 were neutrophils.

$\mathrm{He}$ received a blood transfusion and antibiotics, but his condition deteriorated and he died on 19 February 1969.

\section{Clinical Diagnosis}

(1) Chronic lymphocytic leukaemia.

(2) Multiple pathological fractures.

(3) Hypercalcaemia with metastatic calcification.

\section{Post-mortem Findings}

Professor C. V. HARRISON (2): The body was that of a thin, wasted, middle-aged man, $165 \mathrm{~cm}$. in height and $56 \mathrm{~kg}$. in weight. There were numerous petechiae and ecchymoses over neck, trunk, and limbs. There was a decubitus ulcer over the spine in the lower thoracic region, and slight dorsal kyphosis.

There was marked extension of the bone marrow, together with destruction of bone in the most affected areas (Fig. 1). The marrow in the spinal bodies was increased; there was destruction of bone and collapse of many of the vertebrae, but especially T.7, T.12, L.1, and the ribs were similarly affected, as were the sternum, the right pelvis, the right clavicle, and the left femur. The left acetabulum was considerably eroded. There was lesser involvement of the skull and the scapula. Histological sections from many parts of the skeleton showed the same appearances. The marrow was intensely cellular, and the normal marrow elements had been overwhelmed by a proliferation of relatively well-differentiated lymphocytes. In many areas it was difficult to recognize any original marrow cells. The normal marrow histiocytes contained iron (from transfusion) and also showed considerable phagocytic activity destroying lymphocytes and erythrocytes.

At all the sites examined microscopically-spine, sternum, 


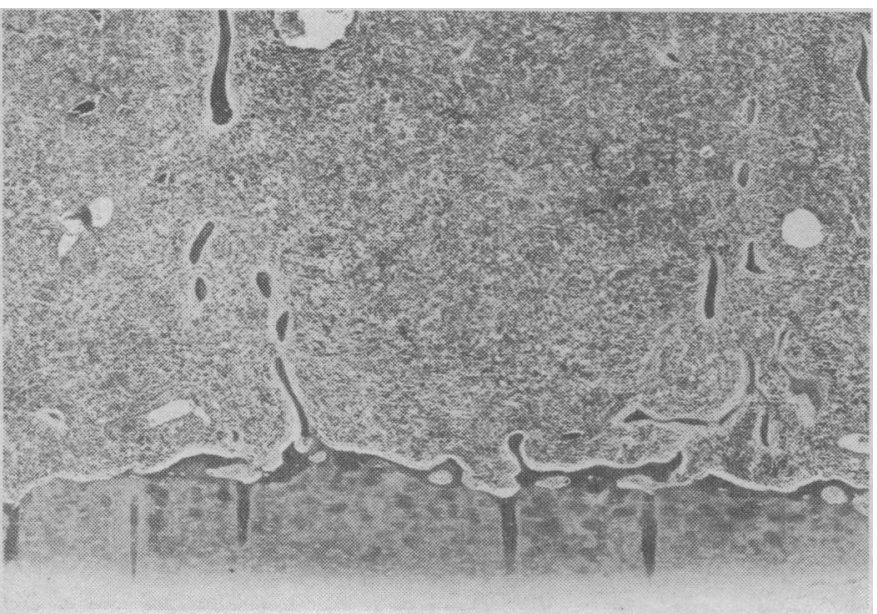

Fig. 1.- Vertebral body showing a very cellular marrow and severe osteoporosis. (H. \& E. $\times 11$.)

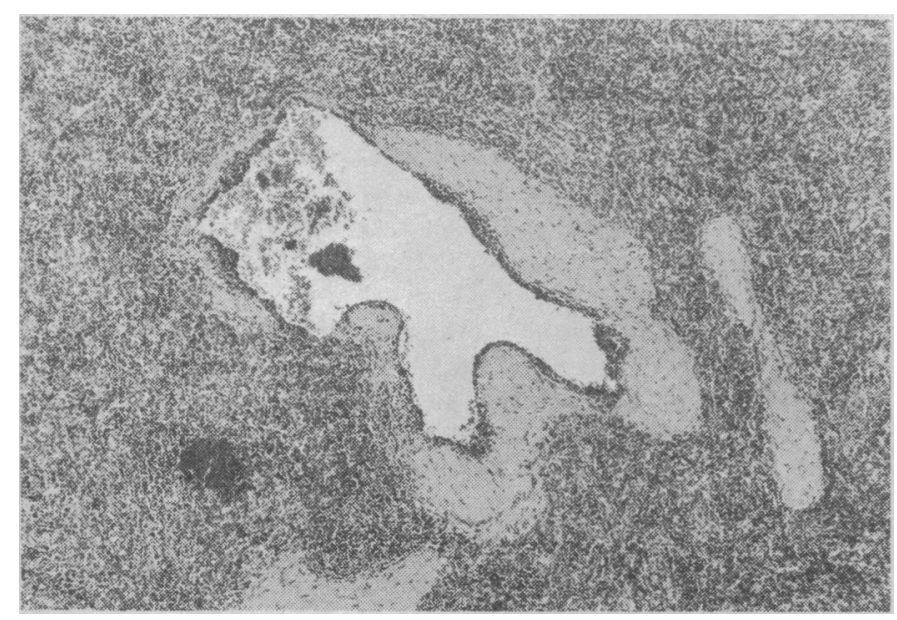

FIG. 3. - Subintimal leukaemic infiltrate in the spleen. (H. \& E. $\times 42$.)

ribs, pelvis, femur-the bone showed greater or lesser degrees of bony destruction. The trabecular bone and sometimes even cortical bone had undergone osteoclastic resorption due to the presence of the leukaemic infiltration (Fig. 2). In many sites, especially spine, there was evidence of old fractures. In addition undecalcified sections showed that there was a mild degree of osteomalacia. There was no evidence of osteitis fibrosa.

Throughout the body lymph nodes were enlarged, but not massively, all being less than $5 \mathrm{~cm}$. and most of them much smaller than this. They were soft and pale. Microscopically the nodes everywhere showed loss of normal architecture and replacement by masses of slightly anaplastic lymphocytes.

The spleen was enlarged to $1,150 \mathrm{~g}$. (normal, $150 \mathrm{~g}$. .). On cutting it showed rather homogeneous, pale, meaty appearances. Microscopically the spleen showed rather patchy lymphoid infiltration of the red pulp, significantly less intense than is seen in most cases of chronic lymphatic leukaemia (Fig. 3). There was slight siderosis.

The heart was of normal size (280 g.) and was healthy except for a small amount of calcification beneath the line of attachment of the posterior cusp of the mitral valve.

There was evidence of tracheitis and bronchitis. The lungs were heavy: left $600 \mathrm{~g}$., right $800 \mathrm{~g}$. Most of the increased weight was due to oedema. In the upper lobe of the right lung about half the tissue was yellowish-white and gritty with calcification. The left lung also showed areas of calcification in

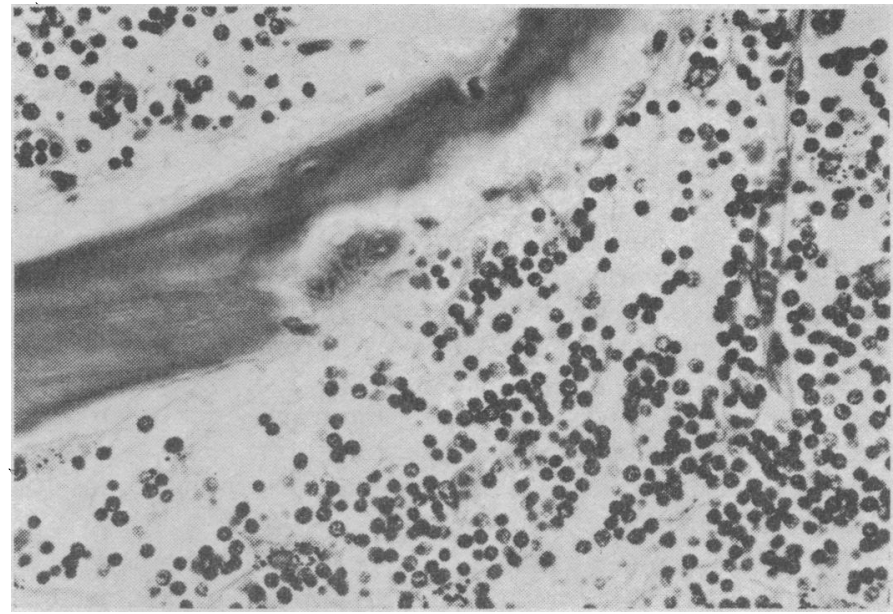

Fig. 2.-High-power view of trabeculum from vertebral body undergoing osteoclastic resorption. Note the uniformly lymphoid cellular marrow of lymphatic leukaemia. (H. \& E. $\times 310$.

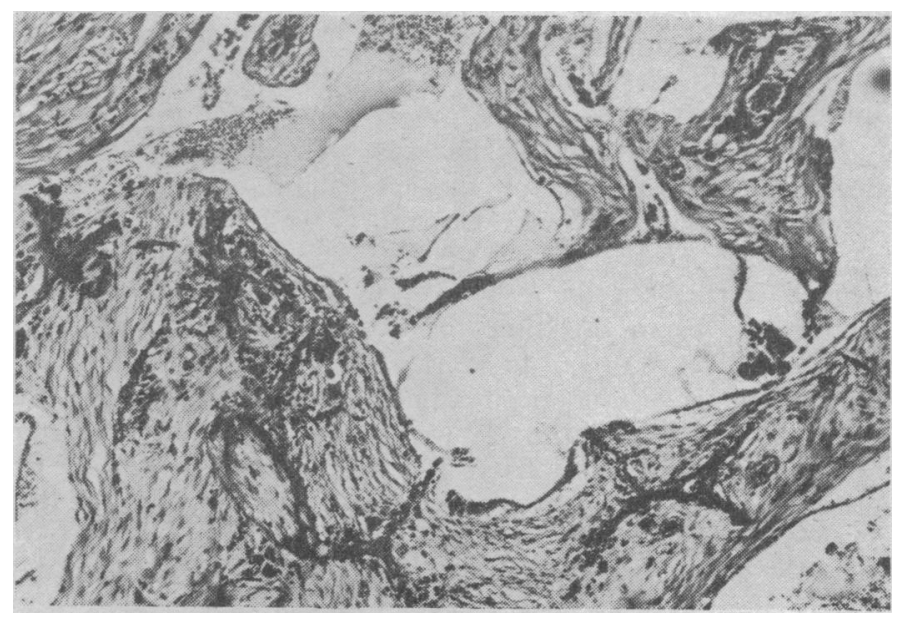

FIG. 4.-Fibrosis and calcification of alveolar walls. (H. \& E. $\times 84$.)

the upper lobe. No pulmonary emboli were found and there were bilateral pleural effusions, $600 \mathrm{ml}$. on the left and $300 \mathrm{ml}$. on the right. Microscopically the gritty areas in the lung showed calcification of alveolar walls (Fig. 4). In these affected areas the alveolar spaces were filled with young fibrous tissue so that the appearances were those of carnification. In one section of the right lung a small pulmonary artery showed scarring suggesting previous embolism. Whether the calcification occurred in an area of previously fibrosed lung or whether the calcification itself induced calcification is uncertain.

There were haemorrhages into the tongue and some superficial ulceration of the tonsils. There were mucosal haemorrhages in the oesophagus, stomach, and small and large intestine, but there was no significant enlargement of the intestinal lymphoid tissue.

The liver was enlarged to $2,600 \mathrm{~g}$. (normal, 1,550 g.). On section it appeared pale, and the portal tracts could be seen to be pale and enlarged. Microscopically the portal tracts were all enlarged to several times normal size and were packed with leukaemic lymphocytes (Fig. 5). There were only relatively scanty lymphocytes in the sinuses. The liver showed slight siderosis presumably due to transfusions.

Thyroid 15 g., normal, though rather small. Parathyroids: Two upper glands were found, and these weighed 15 and $20 \mathrm{mg}$. The lower glands could not be found, though one of them was encountered embedded in the thyroid in the histo- 


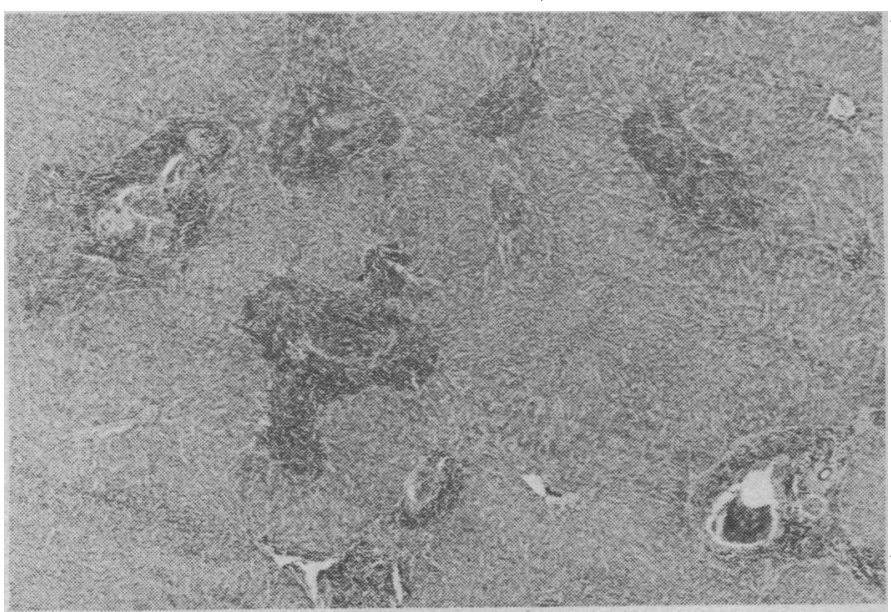

FIG. 5.-Leukaemic infiltrate in the portal tracts of the liver. (H. \& E. $\times 11$.)

logical section of the latter. The combined weight of the upper glands was less than average and the third gland was smaller than average. There was therefore no evidence of parathyroid hyperplasia. Adrenals and pituitary appeared normal.

Both kidneys appeared normal macroscopically: Left $120 \mathrm{~g}$., right $100 \mathrm{~g}$. Microscopically they showed leukaemic infiltration of the cortex. This tended to be patchy around vessels rather than completely diffuse. It did not significantly affect the medulla. In addition there was appreciable microscopic calcification in tubules, apparently mainly in the second convoluted tubules. The pelves, ureters, and lower urinary tract were normal.

The dura mater showed quite extensive eggshell-like calcification. There was also a small subarachnoid haemorrhage over the left fronto-parietal region measuring about $3 \times 5 \mathrm{~cm}$. in area but only a millimetre or two in depth.

The brain weighed 1,550 g., slightly overweight. On sectioning there were many small petechial haemorrhages mostly around $1 \mathrm{~mm}$. but sometimes up to $4 \mathrm{~mm}$. diameter. Microscopically these various haemorrhages were confirmed. They were all apparently of recent origin, and the ones within the substance of the brain were nearly all perivascular around small arteries and arterioles.

\section{Pathologist's Diagnosis}

(1) Chronic lymphocytic leukaemia.

(2) Extensive secondary bony resorption with multiple fractures and hypercalcaemia.

(3) Metastatic calcification in lungs, dura, and kidneys.

(4) Multiple petechial haemorrhages due to thrombocytopenia.

(5) Terminal pulmonary oedema.

\section{Discussion}

Dr. Galton: The first two and a half years of the patient's illness were relatively uneventful, in that bone marrow function was normal and the only episode of infection was a mild attack of unisegmental herpes zoster. But the lymphoproliferative process was only partially controlled by continuous chlorambucil therapy: the spleen and some lymph nodes remained palpable, the absolute lymphocyte count was persistently slightly raised, and the bone marrow remained heavily infiltrated with lymphocytes.

The second period of 18 months was characterized by recurrent life-threatening infections, associated with low serum levels of immunoglobulins and by increased activity of the disease, with progressive and massive enlargement of lymph

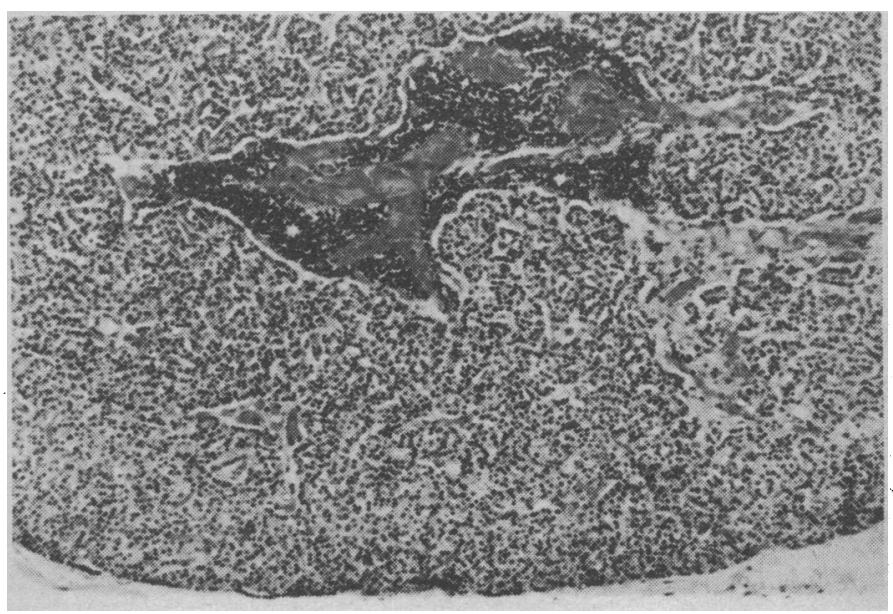

Fig. 6.-Perivascular leukaemic infiltrate in a small but rather cellular parathyroid gland. (H. \& E. $\times 84$.)

nodes and of the spleen and liver, a rising trend in the lymphocyte counts, and progressive impairment of bone marrow function with resulting neutropenia and thrombocytopenia. Cytotoxic therapy was withheld for long periods because of the likelihood of increasing the risk of infection by depressing the already low neutrophil counts. There was evidence of resistance to cyclophosphamide in the last three months of life. Gammaglobulin therapy was given for nine and a half months, but its efficacy was uncertain because the patient suffered an episode of septicaemia secondary to a paronychia while receiving gammaglobulin therapy. Attempts to identify causative organisms were unsuccessful in all but one attack of septicaemia, when three blood cultures all yielded Staphylococcus albus, one of many organisms of low-grade pathogenicity for normal persons that can be highly dangerous for patients suffering from chronic lymphocytic leukaemia.

The exceptional feature of the case was the development in the last 6 months of life of bone pain associated with extensive lytic lesions, osteoporosis throughout the axial skeleton and in some long bones, and collapse of many vertebral bodies. These became manifest at a time when the activity of the disease was maximal, as shown by lymphocyte counts of the order of $400,000 /$ cu.mm., and the massive lymph node enlargement and splenomegaly. Accompanying the bone lesions was persistent hypercalcaemia with widespread metastatic calcification, followed during life by the progress of corneal deposits. A severe sodium-losing nephropathy was thought to be secondary to the nephrotoxic effect of persistent hypercalcaemia. It was satisfactorily controlled by the administration of sodium chloride, while the hypercalcaemia was partially controlled by the administration of buffered phosphates, and it was possible that the relief of pain was also due to the phosphate therapy. However, at the time he was also receiving cyclophosphamide, and the lymph nodes and spleen were diminishing in size and the lymphocyte count was falling.

Local $x$-irradiation of the skull relieved the deafness and nasal congestion that were attributed to lymphoid infiltration of the nasopharynx and neighbouring structures, but did not relieve the bone pain that became increasingly severe in the last weeks of life.

Professor J. V. DAcIE (3): Thank you very much, Dr. Galton. Dr. Doyle, could we discuss the last radiographs?

Dr. F. H. DoYle (4): This picture is rather unusual in adults with lymphocytic leukaemia and much more like that seen in myelomatosis : discrete areas of bone destruction were widely scattered throughout his skeleton. The rate at which his vertebrae fractured was remarkable. It started in May 1968, at which time he developed a fracture of his 9th thoracic vertebra. By the beginning of February 1969, just 31 weeks later, he 
had fractured 14 of the 15 thoracic and lumbar vertebrae, which we showed radiologically on routine radiographs roughly speaking at the rate of one fracture a fortnight.

Professor Dacie: Dr. Galton, would you like to comment briefly on the findings? Are you surprised at what Professor Harrison has shown us, and, particularly, would you like to tell us whether you feel these bony lesions are common or rare in lymphocytic leukaemia?

Dr. Galton: The most surprising feature of this case was the bony lesions. The majority of patients suffering from chronic lymphocytic leukaemia do get extensive lymphocytic infiltration of their bone marrow, but it must be highly unusual to get bony resorption and lytic lesions of the type that this patient had. There are one or two illustrations in the textbooks on bone lesions in leukaemia, and occasional cases have been described. This degree of bone destruction is unique in my experience.

Professor Dacie: Dr. Doyle, do you agree with this? Are the findings unique in your experience too, bearing in mind that this particular patient had not got myelomatosis?

Dr. Doyle: Yes, I agree with Dr. Galton.

Professor DAcIE: What puzzles me is how this has been brought about. Professor Harrison, have you any views on this? You did mention, I think, resorption of bone because of the presence of lymphocytes. Can you take us any further? What is happening in the bone?

\section{Bone Destruction}

Professor Harrison: I think that what is happening is that the osteoclasts are destroying the bone, as in secondary carcinoma of bone and also in myelomatosis. We do not usually see it in leukaemia. However, this man was kept alive long after any ordinary patient with leukaemia would have died. He had five attacks of septicaemia, had been transfused, and was kept alive by very skilled therapy. Perhaps we are now seeing what has hitherto been impossible.

Professor DACIE: So you are telling us that this is all the result of osteoclastic activity.

Professor HARRISON: I would like to suggest that; I do not think that the lymphocyte is capable of eroding bone on its own.

Professor C. C. Booth (5): I wonder if it is possible that the lymphocyte could be producing a locally destructive hormone in the way that carcinoma of the breast can. If breast cancer tissue from a patient with malignant hypocalcaemia is put on a rat's skull, it will erode the bone.

Professor Harrison: All I can possibly suggest is that in this case the osteoclasts are caught in the act. I don't really know whether they are solely responsible.

Dr. DOYLE: It is very interesting that in this patient the parathyroids were, if anything, smaller than normal.

Dr. J. R. HobBs (6): The point I would stress is not so much the activity of the osteoclast as the lack of activity of the osteoblast. I don't know where the alkaline phosphatase of 24 came from, but I have our laboratory record here. We have measured it 18 times and it was never higher than 13 K.A. units, and frequently subnormal. In this finding there is an overlap with myelomatosis, where there is the same resorption of bone without any increase in alkaline phosphatase. Somehow or other the tumour inhibits osteoblastic activity. Perhaps it is this lack of osteoblastic repair rather than the activation of osteoclasts that enables holes to be formed.

Dr. D. Evans (7): It is rather hard to explain the elevation of serum calcium on those grounds, is it not, Dr. Hobbs?

Dr. HobBs: In this case we did not find hypercalciuria. Most of the time his blood urea was $150-200 \mathrm{mg}$./100 ml., and because of this renal failure any excess calcium from un- opposed pressure erosion of bone would accentuate his hypercalcaemia.

Professor DACIE: Dr. Evans, can the mere expansion of the lymphocyte population in bone lead to the disappearance of the structure of the bone?

Dr. Evans: I agree with Professor Harrison that the erosion is being produced by osteoclasts. I don't think this is an effect of pressure, because in some cases with extensive carcinoma of the bone (for instance, in carcinoma of the prostate) we do not have osteolysis. I think the speculation that it may be a substance like parathormone released by tumour locally or generally is very reasonable. The findings of Gordon and Cantino $^{1}$ in breast carcinomas are interesting in this respect but are not yet substantiated.

Dr. G. Joplin (8): On the other hand there is another possibility-that there is a local pressure problem, and that the osteoclasts are merely acting as a secondary mopping-up operation without necessarily being primarily responsible for bone resorption; it may well be that the majority of bone resorption that is carried out in the normal individual is not by fully formed solid osteoclasts but by small round cells.

Professor DACIE: Professor Harrison, you are challenged. Do you agree with Dr. Joplin?

Professor Harrison: I would like his evidence for these small round cells. The term is not very precise.

Professor DACIE: Dr. Joplin, do you know what these cells are?

Dr. Joplin: There was a very interesting study carried out by Professor Irving in Boston ${ }^{2}$ in which bone was transplanted from one animal to another, the donor having been labelled with tritiated proline. When the bone was removed from the recipient there was an accumulation of small round cells all over the surface, and it was quite evident that these cells had now become labelled. That is the type of small nonspecific round cell about which I have been talking.

Professor DACIE: Dr. Wrong, what about the salt-losing state? I think you were probably consulted about the management of this patient at various times.

Dr. O. M. WRONG (9): This sort of patient with sodiumlosing renal disease has usually got signs of dehydration (in particular loss of subcutaneous elasticity and hypotension), loss of weight, and renal failure. The diagnosis is confirmed by measuring the urinary sodium, which is high, and it was in this patient. The common causes include obstructive renal disease and hypercalcaemic renal damage. This patient could have had both when first seen by us. He had a high blood urate, which would have raised the problem of uric acid sludge or uric acid calculus obstruction, and he was hypercalcaemic.

\section{Allopurinol and Antimitotic Therapy}

Professor DACIE: This patient, you said, was hyperuricaemic; he was treated with allopurinol. Is this mandatory in a patient treated with antimitotic drugs for leukaemia? Do you recommend it?

Dr. WRONG: The thing which worries me about allopurinol is that sooner or later one is going to see troubles with xanthine calculi. In fact, I can say "sooner," because this complication of allopurinol treatment has been reported in the Lesch-Nyhan syndrome. Seegmiller has pointed out that it is much more likely to occur with great overproduction of purines, as in the Lesch-Nyhan syndrome. This patient also had a great overproduction of purines, and I suspect that such people are in danger of developing xanthine calculi when given allopurinol.

Professor DACIE: Now let us change the topic. What about the immunoglobulins? Dr. Hobbs, is hypogammaglobulinaemia a common finding in chronic leukaemia? 
Dr. HoBBS: It is typical of chronic lymphocytic leukaemia. In a large study $I$ found ${ }^{3}$ that the reticuloendothelial diseases that have the longest natural history tend to get the most severe hypogammaglobulinaemia. It is a slow process, and chronic lymphocytic leukaemia normally goes on for some ten years before the patient comes to us. It is quite common for the late patient to show and suffer from hypogammaglobulinaemia.

Professor DAciE: This man's disease evolved rather rapidly. He was a relatively young man, and in young patients a rapid evolution is common. What is the cause, do you think, of the hypogammaglobulinaemia? What are your hypotheses?

Dr. HoBBS: In chronic lymphocytic leukaemia the level of IgM-globulin is typically reduced more than that of IgAglobulin, and both are more reduced than that of IgG-globulin. On the other hand, with bone marrow aplasia or extensive cancer metastases in the bone marrow the IgG-globulin level is usually reduced alone, the $\operatorname{IgA}$ and $\operatorname{IgM}$ levels being normal. This is presumably because some $60 \%$ of the $\mathrm{IgG}$ production occurs in the marrow, whereas $\operatorname{IgM}$ and $\operatorname{IgA}$ are probably mainly produced elsewhere. Thus, in chronic lymphocytic leukaemia I do not think the immunoglobulin levels are reduced by occupation of the bone marrow.

Professor DACIE: This sounds like a sort of feedback.

Dr. HobBs: I think these leukaemic cells produce a substance which switches off the normal humoral antibody-producing cells.

Professor DACIE: Has anybody else any views on the causation of hypogammaglobulinaemia?

Professor BooTH: I just wonder if there was any evidence that this was so-that is, a normal population of normal cells in these patients-or is there reduction of the plasma cell population?

Dr. HoвBs: By the time they have got hypogammaglobulinaemia they have had a reduction in their plasma cell population.

Professor BooTH: Is there failure of production of immune cells rather than any increased production of a humoral substance?

Dr. HobBs: I don't know. What I am trying to say is that I think the production of immunoglobulins via precursor cells turning into plasma cells is inhibited by some humoral substance from these leukaemic cells. It is not a displacement effect due to space occupation by the leukaemic cells.

Professor Booth : An effect on cell turnover?

Dr. HoBBs : I don't know what normally regulates precursor cells turning into plasma cells which can release immunoglobulins, or whether the precursor population is itself reduced in chronic lymphocytic leukaemia. Dr. Gilmore Harris and I once studied a spleen, removed from a patient with hypogammaglobulinaemia, which contained giant follicular lymphoma. A frozen and thawed homogenate of this human spleen profoundly inhibited rabbit spleen cells from producing antibody against sheep red cells. A control homogenate from a normal human spleen did not achieve the same degree of inhibition. In these experiments the precursor cells had already been formed by prior challenge of the rabbit with sheep red cells. Presumably some humoral factor prevented their transformation into antibody producers.

Professor DACIE: Is there any evidence in this patient of what his immunoglobulins were before he developed leukaemia?

Dr. HobBs: No, but in other patients with chronic lymphocytic leukaemia there is clear evidence of normal levels early on in the disease. In nearly all cases of chronic lymphocytic leukaemia any hypogammaglobulinaemia is slowly and truly acquired; it is secondary to leukaemia.

Professor DAcIE: Dr. Brain, you helped, I know, in the management of this patient. He was plagued by septicaemic infection. Have you any comments on the management of infection in this patient?

Dr. M. C. Brain (10): I think the only comment one can make is that it is important to recognize the recurrence of septicaemia. This man's history illustrates particularly well the fact that one's ideas on the pathogenicity of organisms have to be revised in people susceptible to infection. Though I think there was initial doubt about the significance of the Staph. albus cultured from blood, the organism was cultured repeatedly and the patient responded very satisfactorily to treatment with the appropriate antibiotic. I think the important thing is to recognize that patients with leukaemia are susceptible to infection with normally non-pathogenic organisms which may be on their skin or in their pharynx. For this reason it is highly important that bacteriologists report on all the organisms they culture.

Professor DACIE: Dr. Galton, how successful is gammaglobulin therapy in the prophylaxis of infection in these patients?

Dr. Galton: It is difficult to make out a good case for it.

Professor DACIE: Do you say you don't recommend this as a routine therapy in patients with hypogammaglobulinaemia?

Dr. Galton: I intended to express uncertainty

Professor Booth: I would like to ask what his chronic diarrhoea was due to; this seems to have been a major problem.

Professor HARRISON: May I answer by the negative? He did not have leukaemic infiltration of his intestinal lymphoid tissue.

Professor DaciE: Well, like so many other aspects of this case, the answer is that we don't know, and we certainly don't know the cause of the leukaemia.

\section{ApPointMent OF SPEAKERS}

(1) Dr. D. A. G. Galton, Honorary Director, M.R.C. Leukaemia Therapy Unit.

(2) Professor C. V. Harrison, Professor of Morbid Anatomy.

(3) Professor J. V. Dacie, Professor of Haematology.

(4) Dr. F. H. Doyle, Reader in Diagnostic Radiology.

(5) Professor C. C. Booth, Professor of Medicine.

(6) Dr. J. R. Hobbs, Senior Lecturer in Chemical Pathology.

(7) Dr. D. Evans, Lecturer in Morbid Anatomy.

(8) Dr. G. Joplin, Lecturer in Clinical Endocrinology and Consultant Physician.

(9) Dr. O. M. Wrong, Senior Lecturer in Medicine.

(10) Dr. M. C. Brain, Consultant Physician and Lecturer, Department of Haematology and Medicine.

We are grateful to Professor J. P. Shillingford and Dr. E. D. Williams for assistance in preparing this report, and to $\mathrm{Mr}$. W. Brackenbury for the photomicrographs.

\section{REFERENCES}

1 Gordan, G. S., Cantino, T. J., Erhardt, L., Hansen, J., and Lubich W., Science, 1966, 151, i226.

" Irving, J. T., Heeley, J. D., \& Weinstock, M., in 5' Symposium Européen, Les Tissus Calcifiés, p. 353. Paris, Société d'Edition d'Enseignement Supérieur, 1968.

3 Hobbs, J. R. Proceedings of the Royal Society of Medicine, 1968, 61,883 